$\underline{\text { Supplementary Information }}$

\title{
Dual elements coupling effect induced modification from surface into bulk lattice for Ni-rich cathode with suppressed capacity and voltage decay
}

Yong Ming, ${ }^{\dagger}$ Wei Xiang, ${ }^{\dagger}, \perp$ Lang Qiu,${ }^{\dagger}$ Wei-Bo Hua,${ }^{\S}$ Rong Li, ${ }^{\dagger}$ Zhen-Guo Wu,,,$\dagger$ Chun-Liu Xu, ${ }^{\dagger}$ Yong-Chun Li, ${ }^{\dagger}$ Dong Wang, ${ }^{\dagger}$ Yan-Xiao Chen, ${ }^{\dagger}$ Ben-He Zhong, ${ }^{\dagger}$ FengRong He, ${ }^{\perp}$ Xiao-Dong Guo*,

${ }^{\dagger}$ College of Chemical Engineering, Sichuan University, Chengdu, 610065, PR China.

$\$$ College of Materials and Chemistry \& Chemical Engineering, Chengdu University of Technology, Chengdu, 610059, PR China.

§Institute for Applied Materials (IAM), Karlsruhe Institute of Technology (KIT), Eggenstein-Leopoldshafen 76344, Germany.

${ }^{\perp}$ Post-doctoral Mobile Research Center of Ruyuan Hec Technology Corporation, Guangdong, Ruyuan, 512000, PR China.

${ }^{*}$ Corresponding authors:

Xiao-Dong Guo

*E-mail addresses: xiaodong2009@scu.edu.cn (X.-D. Guo)

Zhen-Guo Wu

*E-mail addresses: zhenguowu@scu.edu.cn (Z.-G.Wu) 
(a)

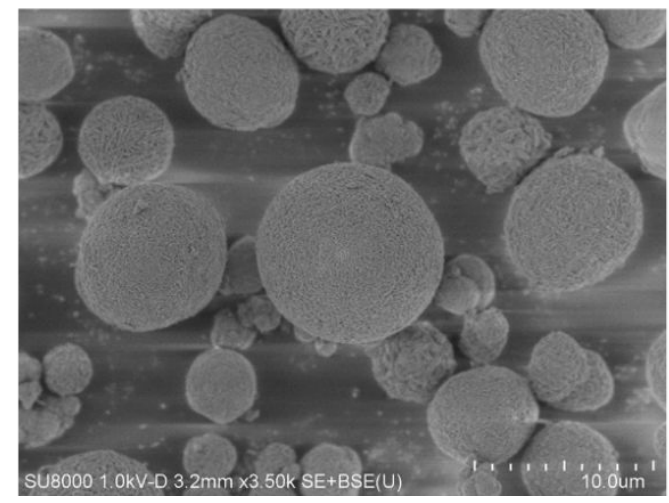

(b)

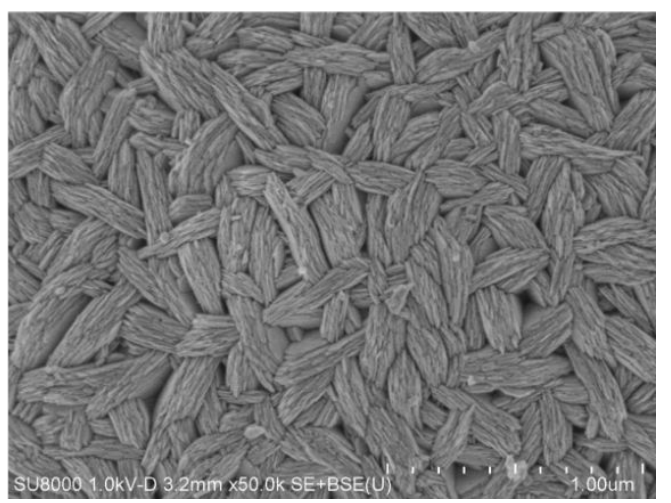

Figure S1. The morphology of the $\mathrm{Ni}_{0.83} \mathrm{Co}_{0.12} \mathrm{Mn}_{0.05}(\mathrm{OH})_{2}$ precursor secondary particles in different magnification.

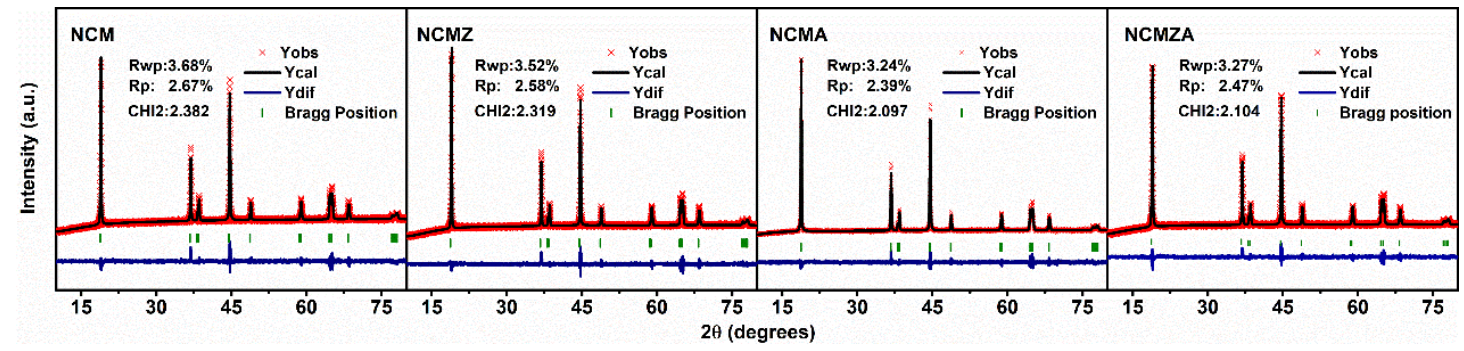

Figure S2. Rietveld refinement results of (a)NCM, (b)NCMZ, (c)NCMA and (d)NCMZA.

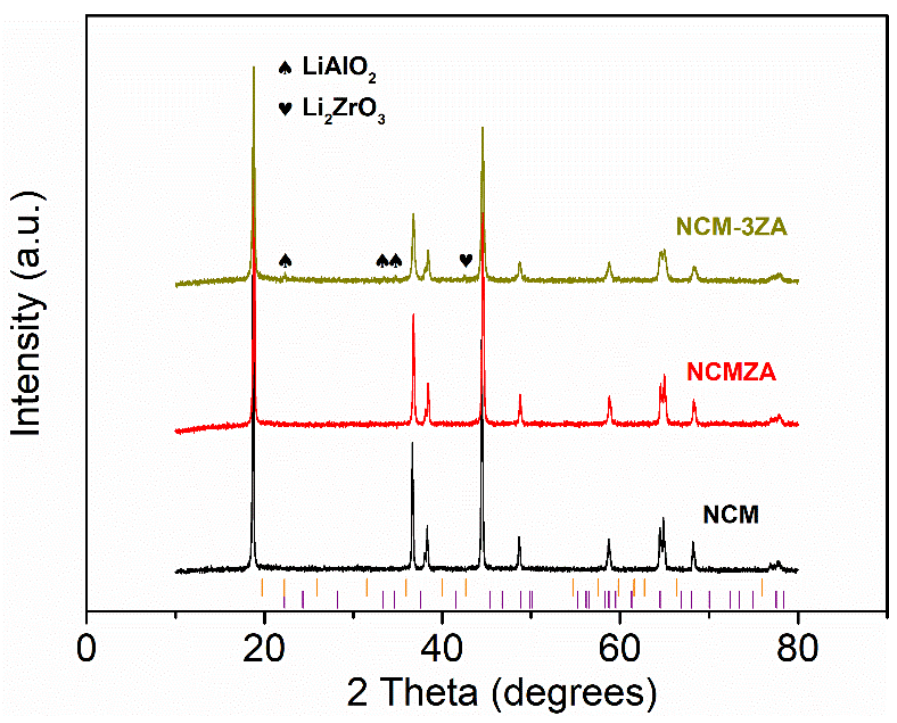

Figure S3. XRD pattern of NCM, NCMZA, NCM-3ZA samples. 
(a)

(b)

(c)

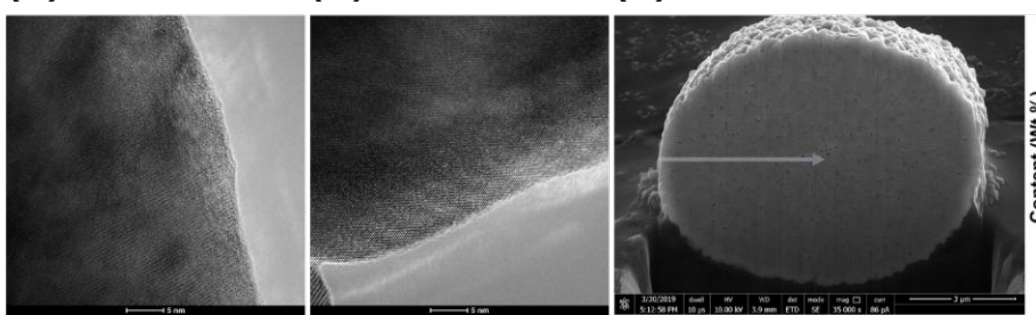

(d)

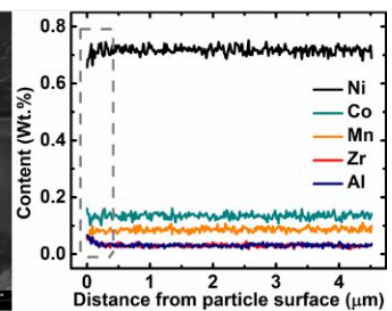

Figure S4. HRTEM image of (a) $1.15 \mathrm{~mol} \% \mathrm{Zr}$ and (b) $1.15 \mathrm{~mol} \% \mathrm{Al}$ modified materials; (c)Cross-section SEM image of NCMZA acquired by FIB; (d)Corresponding counts content distribution of $\mathrm{Ni}, \mathrm{Co}, \mathrm{Mn}, \mathrm{Zr}$ and $\mathrm{Al}$ along the arrow in (c).
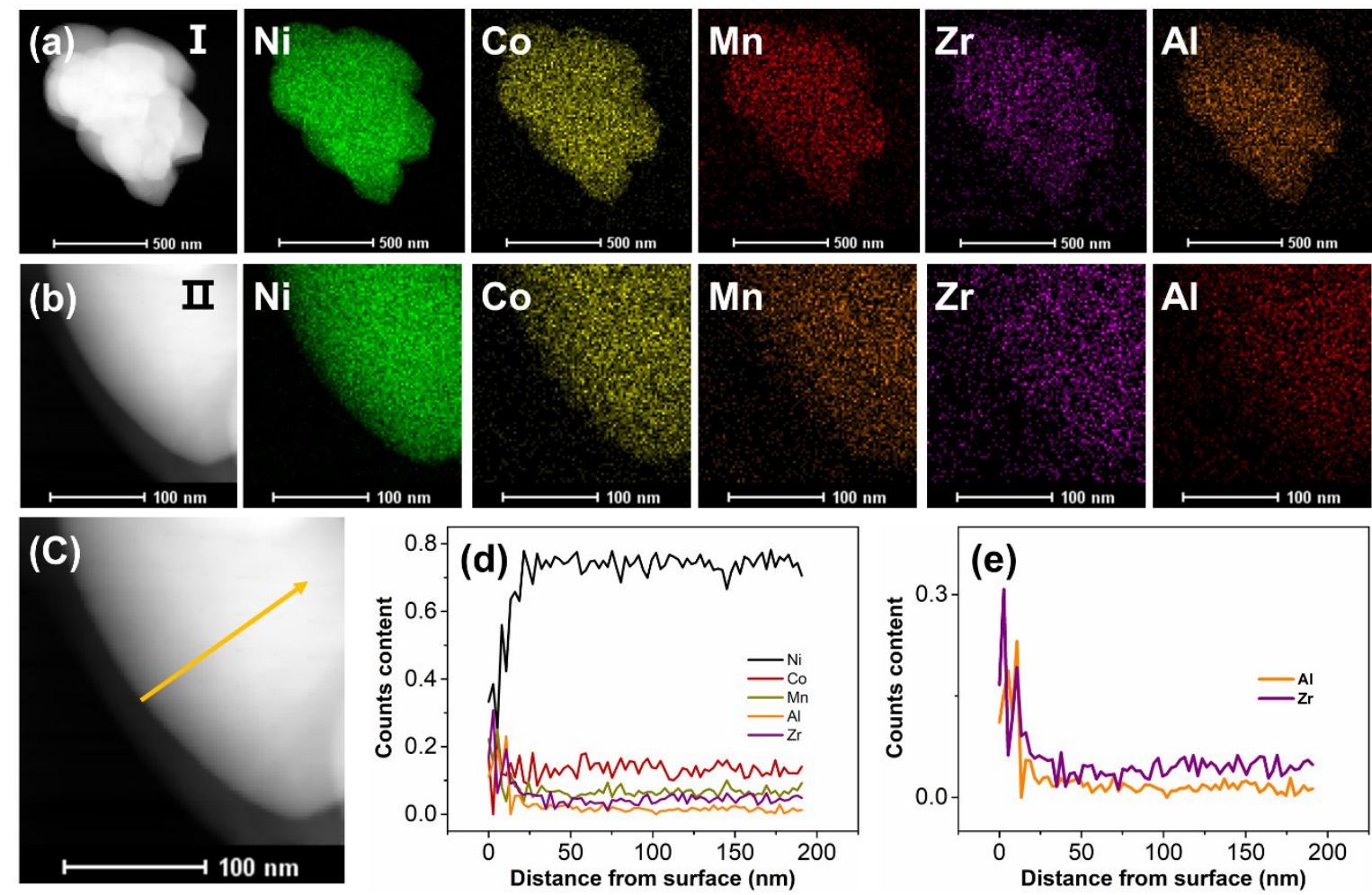

Figure S5. Spatial distribution of $\mathrm{Ni}, \mathrm{Co}, \mathrm{Mn}, \mathrm{Zr}, \mathrm{Al}$ in the primary particle of NCMZA. (a)(b) STEM-HAADF images of different primary particles in NCMZA; (c) A large view of (b); (d) Atomic compositional profile counts content of $\mathrm{Ni}, \mathrm{Co}, \mathrm{Mn}, \mathrm{Zr}$ and $\mathrm{Al}$ along the arrow in (c); (e) The enlarged view of $\mathrm{Zr}$ and $\mathrm{Al}$ compositional profile in (d), indicating enrichment of $\mathrm{Zr}$ and $\mathrm{Al}$ on the surfaces. 
(a)

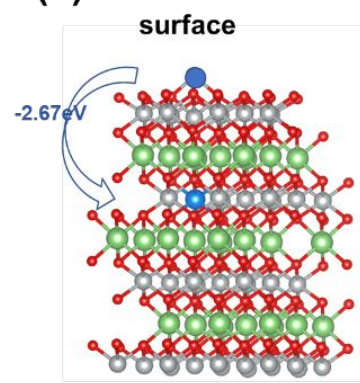

(b)

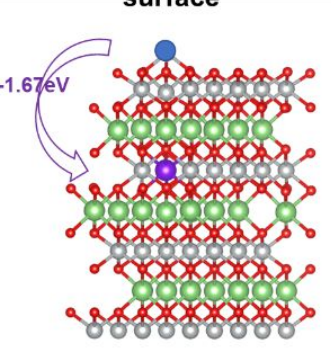

(c) surface

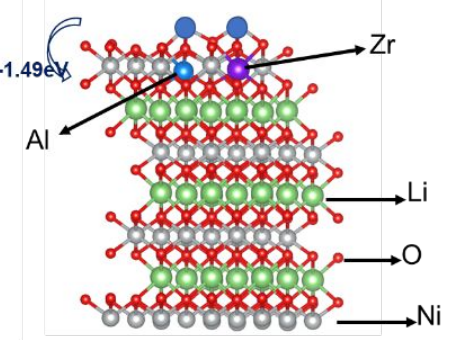

(d)

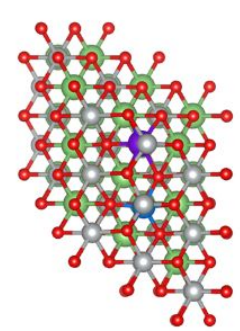

Figure S6. Side view of the structures (a)Al; (b) Zr; (c) dual Al-Zr incorporated $\mathrm{LiNiO}_{2}$; (d) the top of view of (c).

(a)

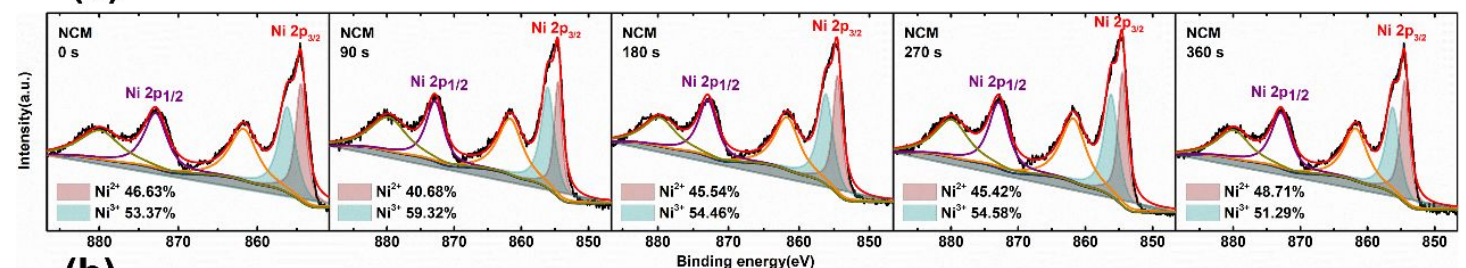

(b)

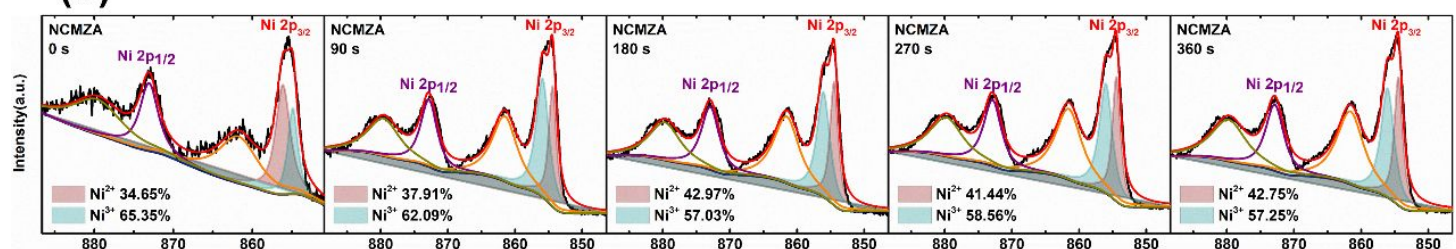

(c)

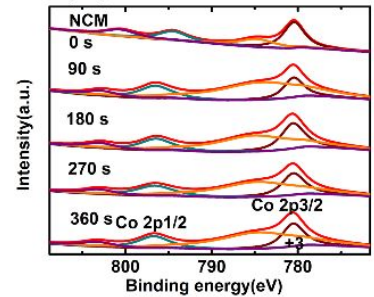

(g)

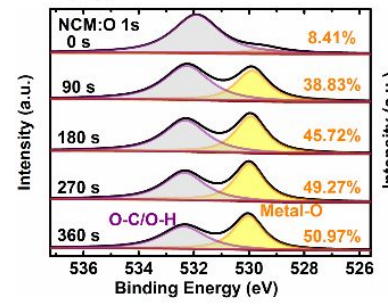

(d)

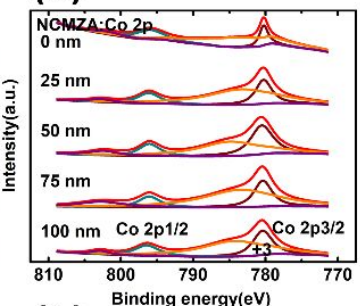

(h)

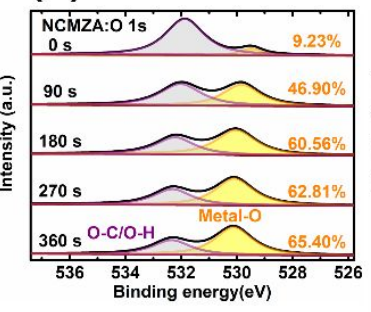

(e)

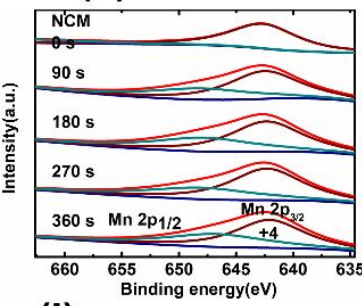

(i)

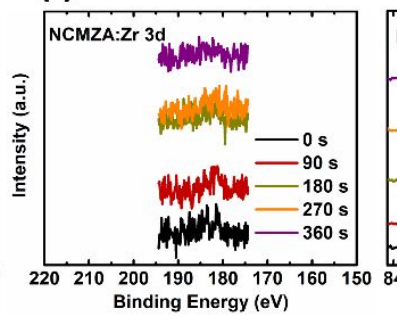

(f)

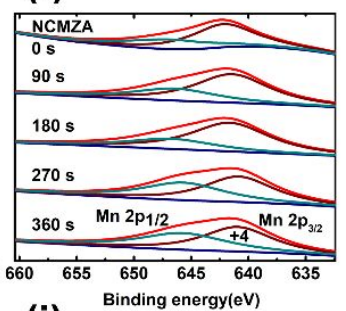

(j)

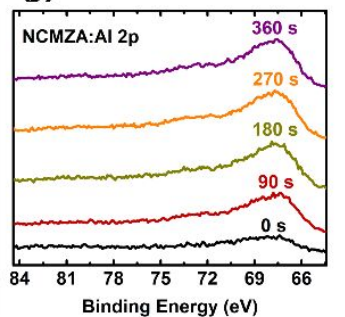

Figure S7. Ni 2p XPS spectra of (a) NCM and (b) NCMZA; Co 2p XPS spectra of (c) NCM and (d) NCMZA; Mn 2p XPS spectra of (e) NCM and (f) NCMZA and O 1s XPS spectra of (g) NCM and (h) NCMZA and the XPS spectra of (i) Zr as well as (j) Al for NCMZA after etching time 0s, 90s, 180s 270s and 360s. 
(a)

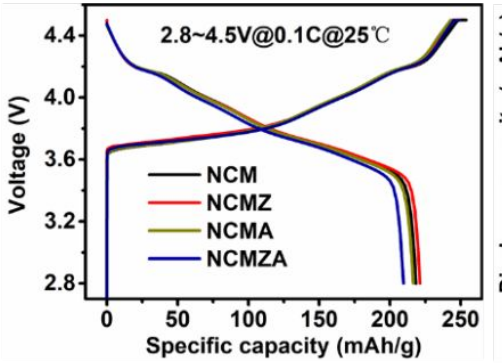

(b)

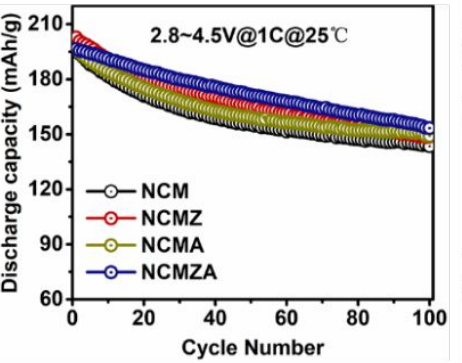

(c)

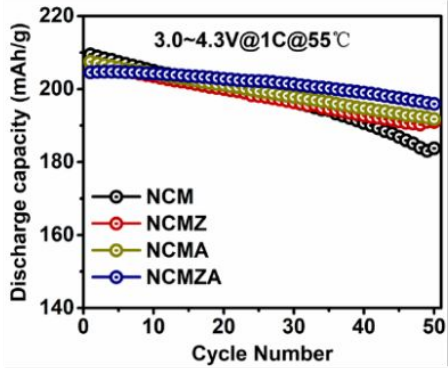

Figure S8. (a)The initial charge and discharge curves; (b) Cycle performance in the potential range of $2.8 \sim 4.5 \mathrm{~V}$ at $25^{\circ} \mathrm{C}$ at $1 \mathrm{C}\left(1 \mathrm{C}=170 \mathrm{mAh} \mathrm{g}^{-1}\right)$; (c) Cycle performance in the potential range of $3.0 \sim 4.5 \mathrm{~V}$ at $55^{\circ} \mathrm{C}$ at $1 \mathrm{C}$.

Table S1. Element composition of designed and measured value form ICP-AES for all samples.

\begin{tabular}{|c|c|c|c|c|c|c|c|c|c|c|}
\hline \multirow{2}{*}{ Sample } & \multicolumn{5}{|c|}{ Designed mole ratio } & \multicolumn{5}{|c|}{ Experimental mole ratio } \\
\hline & $\mathbf{N i}$ & Co & Mn & $\mathbf{Z r}$ & Al & $\mathbf{N i}$ & Co & Mn & $\mathbf{Z r}$ & Al \\
\hline NCM & 0.8300 & 0.1200 & 0.0500 & $\mathbf{0}$ & $\mathbf{0}$ & 0.8339 & 0.1186 & 0.0475 & $\mathbf{0}$ & $\mathbf{0}$ \\
\hline NCMZ & 0.8288 & 0.1198 & 0.0499 & 0.0015 & $\mathbf{0}$ & 0.8304 & 0.1190 & 0.0493 & 0.0013 & $\mathbf{0}$ \\
\hline NCMA & 0.8217 & 0.1188 & 0.0495 & $\mathbf{0}$ & 0.0100 & 0.8306 & 0.1153 & 0.0454 & $\mathbf{0}$ & 0.0087 \\
\hline $\begin{array}{c}\mathrm{NCMZ} \\
\mathrm{A}\end{array}$ & 0.8205 & 0.1186 & 0.0494 & 0.0015 & 0.0100 & 0.8261 & 0.1170 & 0.0472 & 0.0011 & 0.0086 \\
\hline
\end{tabular}

Table S2. The total energy of $\mathrm{E}_{\mathrm{s}}, \mathrm{E}_{\mathrm{d}}, \mathrm{E}_{0}$ for $\mathrm{Al}, \mathrm{Zr}$ and dual $\mathrm{Al}-\mathrm{Zr}$

\begin{tabular}{cccc}
\hline Energy & $\mathrm{Al}$ & $\mathrm{Zr}$ & $\mathrm{Al}$ and $\mathrm{Zr}$ \\
\hline $\mathrm{E}_{\mathrm{s}}(\mathrm{eV})$ & -730.468 & -737.05 & -744.765 \\
$\mathrm{E}_{\mathrm{d}}(\mathrm{eV})$ & -733.137 & -738.718 & -746.253 \\
$\mathrm{E}_{0}(\mathrm{eV})$ & -2.67 & -1.67 & -1.49 \\
\hline
\end{tabular}

